\title{
A Experiência do Desemprego em Portugal Elaboração duma Tipologia ${ }^{1}$
}

Laurense Loison *

\begin{abstract}
$\mathrm{R}$ experiência específica da sua vida activa?

Neste artigo, relacionam-se os factores estruturais da experiência do desemprego com a análise das representações que os desempregados fazem da sua situação e os seus modos de viver essa condição social. Para isso, construiu-se uma tipologia das vivências do desemprego a partir de uma centena de entrevistas com desempregados, numa zona rural e numa zona urbana.

Evidenciamos que o modo de regulação social do desemprego em Portugal protege, numa certa medida, contra a estigmatização e, simultaneamente, oferece às pessoas privadas de emprego, numerosas compensações em termos de integração social e de recursos económicos. De facto, a maioria dos autores referem-se a Portugal como uma sociedade de "pobreza integrada". A tipologia proposta, mostra que uma vivência do desemprego de características "tradicionais" é ainda mais numeroso em Portugal do que uma vivência do desemprego, característico da sociedade salarial providencial que começa a aparecer:
\end{abstract}

Palavras-Chave: desemprego; Portugal; emprego; Estado-providência; solidariedade familiar; trabalho informal; produção doméstica.

\section{Introdução}

Na sequência do crescimento endémico do desemprego nas sociedades ocidentais, várias investigações sociológicas foram feitas, em diferentes países europeus (Schnapper, 1981; Gallie et al., 1994). As pesquisas evidenciaram que o desemprego tem uma grande probabilidade de se traduzir, para as pessoas que o vivem, numa sensação de fracasso, em particular quando a duração de privação de trabalho se prolonga. O desemprego é, muitas vezes, causa de uma degradação do nível de vida, um afastamento da vida social, uma marginalização face a outros trabalhadores, efeitos que podem acumular-se e provocar uma situação de pobreza extrema, na fronteira da ruptura social. Esses estudos mostraram também que a ausência de emprego não produz, em todo o lado, os mesmos níveis e os mesmos tipos de exclusão social (Gallie e Paugam, 2000a) e actua de maneira diferente ao nível dos laços familiares nos diferentes países e mesmo, às vezes, conforme as regiões.

Uma análise aprofundada da sociedade portuguesa, permitiu analisar o fenómeno do desemprego neste país, realidade pouco conhecida pelos sociólogos franceses. A hipótese de partida desta investigação é que o estatuto do desempregado é menos difícil de suportar do que noutros países europeus - como a França - devido a duas razões principais: por um lado, neste país, muitas pessoas não têm interiorizado a lógica da condição de assalariado bem como a da proteç̧ão do Estado-providência e, por outro lado, estamos perante uma integração social bastante forte, acompanhada de uma actividade subterrânea intensa.

\footnotetext{
Assistente Convidada na Universidade de Le Havre

Contacto: 5, place des Jacobins, 38130 Echirolles, France.Tel.: 00334764059 58. E-mail: laurloison@yahoo.com

' Este artigo decorre de uma investigação realizada no âmbito duma tese de doutoramento em sociologia intitulada: A experiência do desemprego em Portugal. Gostava de agradecer a D. Schnapper pelas as suas sugestōes e criticas.
} 
Neste estudo, optou-se pelo estudo do sentido que os indivíduos desempregados dão a esta experiência particular da sua vida activa. Nesse sentido, tenta-se pôr em relação os factores estruturais da experiência de desemprego com as representações que os desempregados atribuem à sua situação, aos seus modos de vida e à sua reacção à privação de emprego.

Neste artigo, desenvolver-se-á uma tipologia das experiências de desemprego em Portugal, elaborada no quadro desta investigação. Tenta-se entender a diversidade dos sentidos que os indivíduos desempregados dão a esta experiência particular da sua vida activa e os impactes nas formas de construção identitária.

\section{Metodologia}

Para analisar simultaneamente a dimensão macro-social e a dimensão micro-social da experiência do desemprego, este estudo está fundamentado em três tipos de dados: informações bibliográficas, elementos quantitativos e todo um corpus de informações qualitativas obtidas durante o trabalho de campo.

Os dados quantitativos utilizados provêm sobretudo do Eurostat, do Instituto Nacional de Estatística e do livro dirigido pelo D. Gallie e S. Paugam sobre o desemprego na Europa.

A investigação fundamenta-se ainda na análise de noventa e quatro entrevistas semidirectivas realizadas em Portugal, em duas zonas, uma rural (concelho de Belmonte) e a outra urbana (concelho de Cascais), no final de 1998 e no principio de 1999 (Loison, 2002). Entrevistaram-se desempregados inscritos no Centro de Emprego, tanto em Belmonte como em Cascais. Quando o desemprego se prolonga, poderá ser mais difícil de suportar. Portanto, adoptou-se a fronteira mais utilizada, quer dizer: menos de um ano, mais de um ano de desemprego, tentando entrevistar tantos indivíduos numa situação como noutra. Teve-se ainda a preocupação de realizar uma escolha equitativa em termos de número de homens e mulheres, conjugada com uma repartição segundo as idades. As pessoas entrevistadas não foram seleccionadas segundo a sua pertença a uma categoria social específica porque, para isso, era necessário classificá-las simultaneamente segundo o seu nível de rendimento, o seu nível cultural e o tipo de profissão exercida: exercício difícil de realizar em razão nomeadamente da importância da economia subterrânea em Portugal e da inserção profissional instável e imprecisa de muitos desempregados no momento da sua entrada no desemprego. Todavia, quando é possível, esta investigação toma em conta cada um destes elementos separadamente porque têm uma certa importância na experiência do desemprego.

Os conteúdos das entrevistas referenciam a relação com o trabalho e o emprego, a integração social, o investimento pessoal na economia subterrânea e a percepção do futuro.

\section{Resultados}

\section{A Condição Social dos Desempregados em Portugal}

Para bem compreender a condição social dos desempregados em Portugal, estudou-se o modo de integração profissional, a forma de intervenção do Estado-providência e também o papel da solidariedade informal na regulação social do desemprego.

Partimos da hipótese que um certo número de indivíduos não tem interiorizado a lógica da condição de assalariado devido, nomeadamente, a uma percentagem importante de trabalhadores por conta própria no mercado de emprego português (25,9\% das pessoas empregadas, em 1998, contra $14,7 \%$ na UE15), das fracas retribuições do trabalho assalariado e das características da estrutura económica nacional, como por exemplo o imobilismo relativo das pequenas empresas - apesar de tudo numerosas - e a orientação tradicional da produção em geral, em comparação com o conjunto dos países da UE 15. A distinção entre o trabalho e o emprego é fundamental nesta análise. A não-interiorização da lógica da condição de assalariado teria por consequência uma fraca estigmatização do desemprego e, potencialmente, poderia facilitar o facto de compensar a ausência de emprego.

Foi evidente o que constitui a integração profissional em Portugal onde abunda a precariedade de emprego. Numerosos assalariados estão confrontados com a precariedade do emprego praticamente desde sempre. É o caso dos que têm um contrato a prazo (em 1998, 17,4\% dos assalariados estavam nesta situação, contra $12,7 \%$ 
na UE 15) mas também dos que enfrentam um risco relativamente permanente de serem despedidos ou de deixar a empresa (por causa, nomeadamente, dos baixos salários e do incumprimento da legislação do trabalho por parte de alguns empregadores: não pagamento dos salários, não respeito pelo tempo de trabalho semanal ou das pausas (Ramos, 1998), despedimentos sem pré-viso, trabalho informal, etc.).

Também, para perceber a relação com a condição de assalariado em Portugal, é necessário analisar as contrapartidas do trabalho em termos de direitos sociais. Mesmo se parece prometedora, a legislação portuguesa relativa às garantias face aos principais riscos sociais associados ao trabalho e mesmo a situações fora do trabalho, mas a cobertura efectiva não compensa as condições precárias produzidas pelos baixos salários. De facto, a protecção social portuguesa caracteriza-se por fracos montantes das prestações sociais (calculadas em função do nível salarial que é, no seu conjunto, bastante baixo), em comparação com o custo de vida do conjunto dos países da UE 15, e por deficientes modos de funcionamento dessa redistribuição (selectividade das pessoas a ajudar, clientelismo, etc.) (Gough, 1996: 16).

Esta precariedade de emprego impede a emergência de grandes expectativas face ao futuro profissional. Mas as características do mercado de trabalho permitem, ainda, explicar a existência, mais ou menos alargada, de um desemprego mascarado, o que contribui para uma construção mais ténue da categoria social do desempregado comparativamente com o que encontramos nos países do Norte da Europa ${ }^{2}$.

Poder-se-á falar, numa certa medida, de precariedade do trabalho no sentido em que o montante dos salários é muito baixo, em Portugal, em comparação ao custo da vida. Ademais, muitos assalariados realizam tarefas repetitivas que são de pouca gratificação, tendo ao mesmo tempo fracas perspectivas de carreira e muito pouca autonomia no seu trabalho. Lembre-se que o tecido produtivo português é constituído por sectores de actividade tradicionais, devido, em larga medida, ao baixo nível de instrução (em 1998, 20,7\% da população com idade de 25 a 59 anos tinha acabado, pelo menos, o segundo ciclo do ensino secundário, contra 59,9\% na UE 15) e de formação da população activa em geral que não permite o desenvolvimento de actividades de ponta. Por outro lado, uma parte significativa do sistema de emprego favorece produções poucas inovadoras (tecido produtivo fundado numa competitividade pelos custos e pelos preços, abertura à inovação limitada no mundo da empresa (Rodrigues e Lopes, 1993: 15; Freire: 1998)). De facto, muitos activos nem as expectativas em termos de salários e de estabilidade de emprego conseguem ver concretizadas, nem consideram a potencial gratificação que lhes adviria de um trabalho feito com gosto.

Assim, os assalariados valorizam outros elementos no seu trabalho. Trata-se, por um lado, do carácter de socialização permitida pelo trabalho e, por outro lado, de uma forte ética do trabalho. De facto, existe um consenso no seio da população portuguesa relativamente ao papel do trabalho visto, antes de tudo, como um meio de sobrevivência. Esta característica é ainda mais valorizada quanto o Estado-providência é fraco e o trabalho é visto como a única forma de conseguir sobreviver. Enfim, o trabalho faz falta porque a sua ausência pode produzir graves problemas financeiros mas também porque a pessoa que está privada de trabalho não pode dar prova da sua fidelidade aos outros e aos valores da sociedade nem é exemplo social reconhecido. Assiste-se assim a uma devoção ao trabalho em todas as ocasiões mesmo quando é pouco interessante e pouco remunerado. "Ser trabalhador" é uma qualidade a transmitir às crianças julgada mais importante em Portugal que nos outros países europeus (França, 1993: 32). Por isso, a integração profissional, em Portugal, está essencialmente baseada numa ética do trabalho intensa, similar à que encontramos nas sociedades tradicionais artesanais ou camponesas.

A relação com o Estado-providência influencia igualmente a experiência do desemprego. O nível de indemnização em situação de desemprego é fundamental. Se as prestações são fracas, os indivíduos não podem viver em condições semelhantes às que tinham quando trabalham, e assim o risco de ficar desempregado torna-se uma

\footnotetext{
${ }^{2}$ Nesta investigação, a expressão «Europa do Sul» engloba a Espanha, a Grécia, a Itália e o Portugal. O termo «Europa do Norte» inclui os outros países da UE.
} 
grande ameaça. As dificuldades financeiras podem também ser obstáculo à procura de emprego e, assim, agravar o fenómeno de distância do mercado de trabalho. Deste ponto de vista, a fraqueza do Estado-providência português, face ao conjunto dos países europeus prejudica fortemente os desempregados.

O modo de intervenção do Estado-providência, face ao desemprego, tem assim efeitos sobre a experiência desta condição específica. O regime português de ajuda social relativamente a situação de desemprego pode ser qualificado de "subprotector" (Gallie e Paugam, 2000b: 5). De facto, por um lado, as políticas activas de emprego são quase inexistentes (em 1996, as despesas em políticas activas de emprego eram o equivalente de $1,1 \%$ do rendimento bruto dos agregados domésticos (Gallie e Paugam, 2000b : 9). Por outro lado, em Portugal, é baixa a percentagem de desempregados que recebe subsídio de desemprego (apenas 27,3\% de desempregados em 1995 (Gallie e Paugam, 2000b: 8) e quando beneficiam de uma ajuda, o montante é relativamente fraco face ao custo da vida (em 1993, em Portugal, as despesas em prestações de desemprego, por desempregado, representavm 23,7\% do rendimento bruto dos grupos domésticos per capita (Gallie e Paugam, 2000b: 8).

De uma maneira geral, o subsídio de desemprego não permite viver sem outros recursos. Os desempregados portugueses, tal como numerosos assalariados, devem enfrentar graves dificuldades financeiras e muitos mesmo vivem no limiar da pobreza (em 1994, era o caso de 29,6\% dos desempregados (Gallie et al., 2000 : 51) e de $27,1 \%$ do conjunto dos grupos domésticos portugueses, o que indica que o desemprego não tem uma relação directa com a pobreza mas que é o conjunto do sistema económico que produz a pobreza).

Também se confirma o fraco nível de interiorização da lógica do Estado-providência por parte das pessoas privadas de emprego e dos seus familiares. Algumas categorias da população portuguesa não associam os apoios do Estado-providência a um direito do cidadão. Muitas vezes, consideram-nas como caridade. Aliás, muitos indivíduos pensam que são os únicos responsáveis pela sua própria sobrevivência (Dias e Reis, 1993: 293). Isto tem como efeito uma atitude passiva dos desempregados face às decisões institucionais e uma ausência de habilidade para utilizar da melhor maneira as vantagens da protecção social.

Muitos funcionários dos serviços sociais consideram as ajudas do Estado-providência também como caridade. Aliás, devido à falta de meios, são selectivos face às pessoas a ajudar (para a atribuição do Rendimento Mínimo Garantido, por exemplo, devem considerar os rendimentos do trabalho informal, o que deixa um largo espaço à avaliação subjectiva. Capucha, 1998: 30). Por todas estas razões, pode considerar-se que a construção da categoria social do desemprego é menos visível e está menos implantada em Portugal do que nos países do Norte da Europa.

Outra das nossas hipóteses é de que os desempregados estão sustentados social e economicamente pelos seus familiares o que, desta maneira, limita bastante o seu isolamento social e gera participação nas formas de sobrevivência colectiva. Tentámos, assim, perceber os contornos da integração social em Portugal no meio familiar como forma de enfrentar as dificuldades económicas causadas pelo desemprego. Examinámos a intensidade do capital social segundo os indivíduos, e em que medida pode ser utilizado para lutar contra a estigmatização e as múltiplas consequências do desemprego. Também, tentámos determinar a importância dos impactos negativos do recurso a este capital social em termos de nível de vida e de cansaço físico e psicológico de cada um dos membros da família.

Assim, a análise do modo de regulação social do desemprego em Portugal caracteriza-se, simultaneamente, pela incapacidade/recusa de assunção de uma responsabilidade social colectiva e pela forte exigência feita à família relativamente ao facto de tomar conta dos seus membros à procura de emprego. Desta forma, os grupos domésticos adoptam estratégias colectivas para lutar contra os prejuízos económicos do desemprego, associando-se, muitas vezes, a outros grupos domésticos. Por um lado, tentam gastar menos dinheiro através de restrições, da produção doméstica e da entreajuda. Por outro lado, tentam ganhar dinheiro através da economia subterrânea que se encontra generalizada.

Estas estratégias podem funcionar por duas razões. A primeira tem a ver com o facto de que as privações materiais que são originadas pelo desemprego estão pouco relacionadas com uma sensação de vergonha. A segunda está relacionada 
com a existência de uma certa proximidade afectiva com os grupos sociais de pertença.

De facto, a estigmatização que se pensava encontrar devido ao fraco nível do subsídio de desemprego é, com certeza, diminuída pelo facto de que, mesmo em situação de emprego, uma proporção relativamente importante da população partilha a mesma condição social desfavorecida. Por outro lado, a proximidade afectiva com o grupo social de pertença - que tem por origem uma consciência camponesa bem presente no coração do sistema social - é, em parte, responsável, pelo facto de que os cidadãos dão pouco valor as funções do Estado-providência.

Os indivíduos são passivos nas suas relações com as instituições porque em situação de necessidade não são estas que vêm em seu socorro mas as famílias. Assim, a força de trabalho disponível nos grupos domésticos está redistribuída segundo as necessidades e as possibilidades de cada um para ultrapassar as dificuldades económicas que existem devido à ausência de trabalho.

Graças aos rendimentos do trabalho informal, aos diversos intercâmbios com os outros grupos domésticos, à produção doméstica bem como às medidas de restrição, os grupos familiares conseguem, apesar de uma fraca indemnização pública (ou mesmo da ausência de prestações sociais) satisfazer, mais ou menos razoavelmente, as suas necessidades. Mas ainda, estes recursos económicos oferecem aos desempregados, a possibilidade de fazer prova do seu nível de inserção face à comunidade, de ter ritmos espaço-temporais normais e de participar nos intercâmbios económicos e sociais que estruturam a sociedade local. Estas soluções alternativas podem satisfazer algumas necessidades de honorabilidade, de comunicação, de actividade, de mostra de competências, desde que o desempregado não se sinta demasiado estigmatizado para poder aproveitar.

Enfim, o recurso sistemático aos familiares e a proximidade afectiva com o grupo de pertença, permitem a manutenção e, algumas vezes mesmo o reforço, dos laços de sociabilidade durante o desemprego (Paugam e Russell, 2000). Apesar disso, os desempregados mais estigmatizados têm tendência a fechar-se na esfera doméstica. Neste caso, a rede de protecção constituída pelos membros do grupo doméstico e pelos familiares subsiste e impede o isolamento social total.
Todavia, estes modos de compensação reforçam as desigualdades sociais. Aliás, apesar de uma vontade muito forte de suporte, a maioria das vezes, quer o desempregado quer os seus familiares precisam fazer pesados sacrifícios para sobreviverem.

\section{O Tipo-Ideal do Desempregado em Portugal}

A partir do estudo dos factores estruturais, organizámos o tipo-ideal do desempregado em Portugal. Este tipo-ideal corresponde à situação de um indivíduo pouco estigmatizado, em larga medida devido ao fraco grau de protecção do Estado-providência, e à frágil interiorização da condição de assalariado, conjugada com uma forte obrigação normativa das famílias de tomar conta dos seus membros quando estão sem emprego. Este indivíduo pode beneficiar de numerosas compensações económicas (com o risco, em certos casos, de um grande empobrecimento da família), sociais e em termos de identidade, graças a uma integração social relativamente forte, acompanhada da solidariedade organizada a partir da família e do trabalho informal. Parece pois que o desempregado-tipo em Portugal seria, ao mesmo tempo, relativamente pouco sensível, do ponto de vista da sua construção identitária, às alterações da sua vida profissional, e moderadamente constrangido pelo tratamento social e institucional que lhe é atribuído. Aliás, poderia facilmente encontrar, na sua rede de solidariedade, elementos de compensação, pelo menos parcial, pelo facto de não ter emprego.

Este retrato-tipo faz pensar que os desempregados constituem uma população homogénea e que as trajectórias, as potencialidades e as dificuldades são as mesmas para todos. De facto, as observações e entrevistas realizadas em Portugal, mostraram rapidamente a heterogeneidade da população no desemprego.

\section{Elaboração duma Tipologia}

A elaboração duma tipologia é indispensável para compreender a diversidade da realidade. Constitui uma maneira de proceder fundamental para perceber a realidade social no sentido em que 
permite avaliar do melhor modo os efeitos do desemprego. É suposto que os indivíduos possuem uma margem de autonomia que lhes permite apropriarem-se da vida social, negar ou negociar a definição social do seu estatuto. Todavia, o facto de reconhecer uma margem de liberdade aos actores sociais não significa que dominam as regras do jogo na sua globalidade.

Assim, definimos duas séries de indicadores que permitem elaborar uma tipologia dos desempregados em Portugal baseada, ao mesmo tempo, sobre a estigmatização produzida pela situação de desemprego e sobre as possibilidades de compensação face a privação de emprego. A seguir a esta reflexão, evidenciam-se os diferentes factores de variação relativamente ao tipo-ideal. Foi possível tratar da diversidade das experiências do desemprego partindo da ideia de que o indivíduo dispõe de uma margem de autonomia na definição de si mesmo. Portanto, pudemos definir dois tipos de experiência do desemprego em Portugal.

a) Duas séries de indicadores

A partir da análise dos factores estruturais, foi possível deduzir dois eixos de reflexão que permitem bem compreender a experiência do desemprego em Portugal.

\section{A estigmatização no desemprego}

No princípio deste trabalho, considerou-se como hipótese que numerosas categorias da população portuguesa atribuem pouco valor à condição de assalariado e que, por consequência, o choque da ruptura identitária provocada pela perda de emprego é pouco significativa. A seguir, analisou-se que, em Portugal, como noutros países da Europa do Sul, a condição de assalariado é mais desfavorável que nos países do norte. Os salários são, em comparação com o custo da vida, nitidamente inferiores. A competitividade económica está baseada sobre os baixos salários e a qualificação profissional é menor. Enfim, as contribuições do Estado-providência às quais o estatuto de assalariado dá acesso, são de envergadura mais reduzida. Para além disso, pudemos observar o contraste entre os sectores profissionais bem integrados, providos de condições satisfatórias em termos, entre outros, de remu- neração, de tempo de trabalho, de qualificação e os sectores precários nos quais o direito ao trabalho é, muitas vezes, achincalhado, as tarefas pouco qualificadas, os horários penosos, etc.

As pessoas às quais diz respeito a experiência do desemprego são, em maioria, as que não conseguiram integrar o primeiro grupo. Portanto, trata-se dos activos cujas condições salariais são as mais desfavoráveis. Todavia, no seu conjunto, os desempregados consideram o facto de ser assalariado antes de tudo como uma fonte de rendimentos, depois como um meio para participar nos ritmos colectivos e para realizar intercâmbios sociais, fora das actividades realizadas no seio da família e da vizinhança. Lembre-se também que, na sociedade portuguesa, o trabalho é associado a fortes valores éticos.

Partiu-se também da hipótese que a intervenção das instituições encarregadas da protecção social em Portugal tem um efeito pouco marcante para os beneficiários. Durante o trabalho de campo, de facto, pudemos observar a tendência, por parte das pessoas entrevistadas, em afirmar pretenderem uma relação distante com as instituições do Estado-providência. Isto é consequência, simultaneamente, de um fraco grau de interiorização da lógica do Estado-providência por parte de muitos cidadãos e de uma atracção bastante forte destes em direcção dos seus grupos de pertença.

As entrevistas mostraram que a biografia familiar de muitos entrevistados é marcada por condições de vida muito duras. A precariedade material está muitas vezes presente, ao ponto, de chegar a situações dramáticas. $\mathrm{O}$ importante poder discricionário dos trabalhadores sociais conjugado com o facto de que uma parte da população considerar a ajuda institucional como uma questão de caridade do Estado, constituíram um terreno favorável à manutenção de traços próprios a uma cultura da pobreza, amortecendo o desenvolvimento de uma cultura da cidadania. A herança cultural de Portugal conduziu muitos cidadãos a adoptar uma atitude caracterizada pelo fatalismo e a passividade nas suas relações com as instituições do Estado-providência. Desta forma, as práticas sociais dos indivíduos estão impregnadas, pela ideia segundo a qual não há nada a esperar do Estado. As entrevistas evidenciaram a concepção segundo a qual quando somos pobres, não temos direito a nada. Esta representação que os indivíduos 
fazem do Estado-providência tem por consequência o facto de que atribuem pouco significado ao tratamento da sua situação, realizado pelas instituições; e isto mesmo quando recebem ajudas tal como o subsídio de desemprego ou o RMG.

Em Portugal, poucos desempregados recebem uma prestação. As instituições do Estado-providência intervêm perante alguns desempregados quer seja ao título do subsídio de desemprego ou de um subsídio de formação, quer através do RMG. Em todas estas situações, as intervenções do Estado-providência são pontuais e temporárias e as prestações pagas são, no seu conjunto, de um montante bastante fraco relativamente ao custo de vida. $\mathrm{O}$ carácter provisório, a insuficiência dos montantes e a dificuldade para aceder a essas ajudas fazem com que os indivíduos adoptem uma atitude activa para procurar os rendimentos que são necessários. Isto tem como consequência ampliar o facto de que atribuem pouco valor ao tratamento da sua situação pelas instituições do Estado-providência.

Repara-se ainda que o tratamento social do desemprego, em Portugal, só chega a uma diminuta percentagem de pessoas, ao contrário do que foi observado em França por exemplo (Astier, 1992; Demazière, 1992). A definição das condições de atribuição do subsídio definidas na legislação portuguesa são pouco visíveis, exigentes, e nem sempre bem conhecidas. Resulta disto uma fraca estigmatização dos indivíduos que beneficiam duma prestação social relativamente a situação de desemprego.

Enfim, a distância entre o Estado-providência e os cidadãos é ainda maior e os indivíduos crêem só nas suas forças e nas dos seus familiares para enfrentar as dificuldades. Consideram essas forças como o seu único capital social. Os representantes das instituições são considerados estrangeiros nos modos de intercâmbio social, de difícil convivência e cuja maneira de funcionar é pouco compreensível. Dada a relação distante constatada entre os desempregados e as instituições encarregadas de os ajudar, a intervenção destas últimas tem um efeito pouco estigmatizante para os beneficiários.

Assim, devido a um desemprego mascarado bastante importante e a uma cobertura social muita incompleta, com um nível e uma duração de garantia muitas fracas, a categoria social do desemprego em Portugal é menos construída do que no conjunto dos países do Norte da Europa. A estigmatização do desemprego é também menos forte.

Esta fraca estigmatização explica-se também pela forte pressão normativa exercida sobre a rede de parentesco para que sustente as necessidades dos seus membros desfavorecidos. De facto, o sistema de regulação social do desemprego em Portugal repousa sobre a ideia que o indivíduo não deve ser repreendido devido à sua situação de desemprego e que tem direito de partilhar os rendimentos da sua família durante o período de desemprego. Segundo D. Gallie e S. Paugam, neste "modelo familialista", "as responsabilidades relativamente aos desempregados são similares às responsabilidades relativamente aos filhos dependentes" (Gallie e Paugam, 2000c: 371).

\section{As possibilidades de compensação face ao desemprego}

Quando se iniciou esta investigação, considerou-se como hipótese que os desempregados, em Portugal, têm muitas possibilidades à sua disposição para compensar uma parte importante dos prejuízos económicos, sociais e identitários ocasionados pela privação de emprego. Para lutar contra as dificuldades financeiras, uma proporção importante de grupos domésticos organizam de novo a ocupação do tempo de cada um dos seus membros, quer sejam activos em emprego ou no desemprego ou também inactivos, e pensam de novo as despesas e as receitas do grupo. Desta forma, os grupos sociais caracterizam-se pela existência de muitos mecanismos compensadores quer quando o montante dos salários não chega para as necessidades quer no caso da privação de emprego. Esta organização compensadora, no seio dos grupos sociais, ocasiona uma confusão mais ou menos forte segundo os indivíduos e os grupos domésticos, entre estes diferentes tipos de ocupação (as que têm a ver com a actividade profissional, as que são relativas ao trabalho informal o também as que são realizadas no quadro da produção doméstica) e estes diferentes tipos de rendimentos.

A eficácia desta organização sociofamiliar apoia-se sobre relações estreitas com os grupos sociais primários. Estas são pouco alteradas em situações de desemprego. Estes modos de funcionamento têm numerosos efeitos positivos. 
Permitem entreter laços sociais apesar do desemprego, no mesmo tempo que oferecem aos indivíduos a possibilidade de participar, numa certa medida, aos intercâmbios produtivos e sociais que estruturam a sociedade.

Todavia, as possibilidades reais de compensação das consequências nefastas do desemprego, ao nível identitário, não são as mesmas para todos.

b) Os factores de variação

Os resultados desta inquirição mostraram que o sentimento de estigmatização e as formas de compensação que sentem os desempregados varia segundo o sexo, a idade e a maneira como encaram o seu futuro profissional.

\section{O género}

No início do estudo, colocava-se a hipótese que o desemprego em Portugal, à imagem do que foi observado noutros países europeus (Lazarsfeld et al., 1931; Paugam et al., 1993; Whelan e McGinnity, 2000 ; Russell e Barbieri, 2000), devia ser melhor suportado pelas mulheres do que pelos homens. Esta hipótese confirma-se na investigação. Verificou-se também que a persistência do modelo familiar tradicional em Portugal e noutros países do Sul de Europa, poderia explicar a razão porque poucas desempregadas, nestes países, sentem um sentimento de desvalorização do seu estatuto. Em Portugal, nestes grupos sociais e apesar das dificuldades de generalização, raras são as mulheres para quem o desemprego é estigmatizante devido à atribuição de um carácter à sua actividade profissional secundário (Vasconcelos, 1998a : 249, 1998b: 360; Pais, 1993) em comparação, por um lado, com o papel de cônjuge e, por outro lado, com o seu papel no lar e ao lado dos filhos.

Todavia, é preciso notar que, no conjunto, as mulheres não são indiferentes à sua vida profissional. De facto, o trabalho permite que sintam uma independência social e financeira relativamente aos outros membros do seu grupo doméstico. Assim, afirmam-se também fora do universo familiar.

Relativamente aos homens, o trabalho tem uma outra significação. Enquanto que as mulheres valorizam a actividade profissional para adquirirem um espaço de liberdade, fora do que constitui o essencial da sua identidade feminina (mãe, dona de casa), os homens, pelo contrário, atribuem-lhe um alto valor porque lhes permite aderir duma maneira mais forte ainda ao modelo identitário masculino. Neste modelo, o homem deve tomar conta do seu grupo doméstico e deve sempre dar prova da sua coragem e seriedade. É esta a razão que explica que os indivíduos para os quais o desemprego é estigmatizante sejam, na maioria, homens.

Em síntese, o desemprego é estigmatizante porque põe em questão o papel de "bread-winner" do homem, ou seja, um plano essencial da sua construção identitária. Todavia, parece que a estigmatização nos homens parece ser mais importante nos países do Norte da Europa dado que, nestes países, o desemprego atinge, muitas vezes, o estatuto do homem na sua integridade.

Se examinarmos agora as possibilidades de compensação face ao desemprego, podemos dizer que, mesmo se as mulheres, através da sua actividade profissional, tentam distanciar-se do seu papel de donas de casa este estatuto não é de todo rejeitado quando estão desempregadas. Mesmo se lamentam a independência que tinham quando estavam empregadas e se sublinham a monotonia das tarefas domésticas, consagram muito tempo e energia à produção doméstica, em particular ao nível dos cuidados às pessoas (que pertencem ou não ao seu grupo doméstico).

Inversamente ao observado em alguns países do Norte da Europa, e nomeadamente em França (Schnapper, 1981: 75), estas actividades de produção doméstica não são vividas pelas mulheres desempregadas, em Portugal, como um "fingimento de ocupação". Acrescente-se que são numerosas as desempregadas que conseguem ganhar dinheiro com o trabalho informal. Nota-se assim que parece ser assaz fácil o compensar a ausência de emprego na economia informal. É por isso que as mulheres desempregadas entrevistadas manifestam grandes recursos de identidade positiva e conservam, quando estão no desemprego, um suporte social sólido.

Para os homens, as compensações encontram-se, muitas vezes, fora do lar, excepto para os que vivem em zona rural e que consagram uma parte importante do seu tempo à horta e à criação de animais. Desta forma, podem, embora de formas diversas em função das situações, conformar-se ao 
modelo identitário masculino e entreter laços de sociabilidade.

\section{A idade}

Colocava-se também como hipóteses de partida que a idade seria um factor determinante da experiência de desemprego. Esta apreciação provém da leitura de diversos estudos sociológicos relativos a diferentes países europeus. Segundo estas obras, parece que é possível distinguir, de uma forma grosseira, três classes de idades: os jovens, os indivíduos que situam-se no coração da sua vida profissional e os mais idosos. Claro, cada uma destas categorias caracteriza-se por fronteiras fluidas que se movem em função dos factores estruturantes próprios a cada situação de desemprego e duma maneira diferente segundo os indivíduos a quem diz respeito.

Em França, D. Schnapper mostrou que alguns jovens podem fazer a experiência do "desemprego invertido" (Schnapper, 1981). No mesmo sentido, em Portugal, J. M. Pais evidenciou que os jovens podem encarar a instabilidade de emprego de forma positiva (Pais, 1993). Num livro sobre os Jovens portugueses de hoje, o trabalho informal irregular muitas vezes é considerado pelos jovens como uma situação de "não-desemprego" (Nunes, 1998 : 20). Enfim, os jovens portugueses vivem muitas vezes em casa dos seus pais (em 1994, era o caso de $69,8 \%$ dos jovens de 20 a 29 anos (Gallie e Paugam, 2000b: 16), ainda mais quando estão desempregados (era a situação de 74,2\% dos desempregados deste mesmo escalão etário), o que constitui, para eles, um apoio considerável. Todos estes elementos mostram que o desemprego dos jovens pode ser pouco estigmatizante e associado a muitas possibilidades de compensação.

As pesquisas em sociologia mostram que a experiência do desemprego é muito mais dolorosa quando diz respeito a indivíduos que se situam no meio da sua vida profissional. Ademais, parece que, neste escalão etário, os indivíduos que têm entre 40 e 50 anos são os mais susceptíveis de viver o desemprego como uma "ruptura identitária" (Burnay, 2000).

Na Grã-Bretanha, D. Gallie e C. Vogler analisaram a motivação ao trabalho das pessoas desempregadas. As mais idosas aparecem menos motivadas, sobretudo depois de 55 anos: manifestam-se alguns problemas de saúde e a sua socialização começa a orientar-se para o modelo da reforma (Gallie e Vogler, 1994: 131). No seguimento desta reflexão optou-se por entrevistar indivíduos que pertencem a diferentes classes de idade. O material recolhido confirma que a idade é um factor de variação importante face às opiniões e formas de viver o desemprego.

Os jovens que vivem em casa dos pais, e que têm ainda a idade para que esta forma de vida seja socialmente "aceitável", sentem-se relativamente pouco estigmatizados ao não ter emprego, mesmo se todos aspiram a trabalhar. Para os homens, esta ausência de estigma explica-se, em parte, pela sua idade que os autoriza a uma certa "despreocupação". Por esta razão, e ainda porque não têm encargos familiares, não têm a responsabilidade socialmente reconhecida de tomar conta deles próprios e do seu grupo doméstico. Quanto às mulheres, mesmo se aspiram a uma certa independência, convencem-se de forma fácil que ainda têm a idade para estar na tutela dos seus pais.

Esses jovens têm muitas possibilidades de compensação face ao desemprego. Dada a sua idade, o acesso ao apoio dos seus familiares é legítimo, o que faz com que vivam relativamente bem esta dependência. Aliás, os homens têm à sua disposição muitas ocasiões de trabalho informal. Também, são muitas vezes solicitados para prestar serviços aos seus familiares. As mulheres também encontram alguns trabalhos informais a realizar, todavia duma maneira menos frequente que os homens. Estão igualmente muito activas a nível da produção doméstica no seu lar e na sua rede de entreajuda. Enfim, todos estes jovens consagram muito tempo à solidariedade intra-grupo.

É quando os indivíduos estão no centro da idade activa que o desemprego é mais estigmatizante, ainda mais quando estão dependentes dos seus pais e/ou quando são homens e a situação profissional persiste. Para os indivíduos que já têm uma idade avançada e que vivem ainda com os seus pais, o desemprego representa uma humilhação, sobretudo quando se inscreve na duração. Para esses homens, como para estas mulheres, as razões da sua coabitação têm a ver com dificuldades de ordem profissional e afectiva. Solteiros ou divorciados, não conseguem integrar-se de uma maneira estável no mercado de emprego. Têm vergonha da sua situação profissional e sofrem da sua condição afectiva. Têm a tendência de 
perder a noção do tempo que passa e que os atola numa situação que não é reconhecida na sociedade senão negativamente. A humilhação que sentem provoca uma certa falta de vivacidade na procura de emprego e na vida em geral. Para esses desempregados, as compensações são pouco numerosas. Têm tendência a fechar-se na esfera doméstica e a restringir os contactos sociais. A ausência de energia que os caracteriza acaba por limitar as suas possibilidades de compensação tal como o trabalho informal ou a sua contribuição para a rede de entreajuda.

Para os indivíduos emancipados e no seio da sua vida activa, a experiência do desemprego depende muito do sexo e do tempo de desemprego. Relativamente às mulheres, a situação de desemprego é relativamente bem vivida desde que não seja questão de desemprego de longa duração. Quando o desemprego se prolonga, e quando os seus filhos já são maiores não necessitando de tantos cuidados, as mulheres podem sentir sentimentos de estigmatização. Sentem-se então inúteis e só podem repousar sobre um estatuto que julgam insatisfatório. Para essas mulheres, as possibilidades de trabalho informal são restritas pese embora que, para todas, os cuidados aos membros da família e as tarefas domésticas ocupem uma parte importante do seu tempo. Mas ajuízam o seu papel no lar como não sendo uma fonte de desabrochamento das suas identidades.

Relativamente aos homens em plena idade activa, quanto mais persistente é a ausência de emprego, maior é risco que esta situação seja vivida duma maneira negativa. O desemprego é considerado como um signo de mau êxito, de incapacidade a assumir o seu papel de apoio económico do grupo doméstico, quando têm filhos a seu cargo. A sua identidade é ameaçada. Têm medo que alguém possa duvidar da sua seriedade, da sua coragem e das suas forças e angustiam-se pensando na sua idade. Ainda se sentem cheios de recursos e de capacidades, e os numerosos insucessos que conhecem durante a procura de emprego e também as dificuldades na procura de trabalho informal, fazem-nos duvidar da sua utilidade. Sentem-se humilhados pelas recusas e pelo sentimento de não estarem à altura do seu papel. Estes indivíduos tendem a isolar-se socialmente fugindo aos seus vizinhos e amigos. As compensações ao desemprego são poucas.
Os indivíduos no fim da sua vida activa, quer sejam homens ou mulheres, têm uma outra forma de considerar o desemprego. Para os homens, os primeiros meses que sem seguem à perda de emprego podem ser vividos com um sentimento de humilhação. Depois, chega o momento em que a sua perspectiva se modifica. Quando já não têm filhos em casa, os encargos que pesam sobre eles podem ser muito aligeiradas e os seus deveres tornam-se menos presentes. Consideram também que, como já trabalharam muito, chegou o momento de reduzir a sua actividade.

As mulheres reagem de maneira similar. A diferença encontra-se na definição do nível da idade a partir da qual podem estabelecer o fim da sua vida activa, mais cedo do que para os homens. Para todos estes indivíduos, o desemprego constitui a ocasião de aproveitar o prazer dos netos, de prestar serviços aos seus filhos adultos, ou de cuidar dos seus pais ou cunhados idosos. Mesmo se gastam muita energia para serem úteis aos seus familiares, encaram o desemprego como um período de calma e de repouso bem merecido.

\section{A experiência profissional e/ou as perspecti- vas de emprego}

De forma geral, o grau de qualificação do emprego que precedeu o desemprego ou dos futuros empregos (no caso da entrada na vida activa) só faz reforçar as tendências observadas, isto é, se o emprego é pouco qualificado, o estigma do desemprego será menor e as possibilidades de compensação, em termos identitários, serão importantes. É preciso perceber aqui que, quanto maior for a diferença entre a situação profissional passada e/ou esperada e as formas de ocupação durante o desemprego, sobretudo do ponto de vista económico, de reconhecimento social e de prazer na tarefa realizada, mais dificilmente é vivido o desemprego.

No início deste trabalho, considerou-se como hipótese que a experiência do desemprego variava muito segundo o lugar de habitação: zona rural ou urbana. Nesse sentido, considerou-se haver valores diferentes num e noutro meios sociais: mais individualistas em meio urbano o que influenciaria a relação com o trabalho e o emprego, com as instituições do Estado-providência e também nos modos de sociabilidade e na proximidade ao grupo de pertença. $\mathrm{O}$ trabalho de campo permitiu verificar que esta variável é pouco influenciadora na experiência do desemprego. 
Todavia, o lugar de habitação determina o mercado de trabalho no qual os indivíduos tentam inserir-se e também a natureza das actividades de compensação que realizam para viver na ausência de emprego. Assim, relativamente a esta pesquisa, pode-se sublinhar a existência de empregos mais qualificados em Cascais do que em Belmonte e também ocasiões de trabalho informal mais frequentes e mais diversificados em meio urbano. Desta forma, o local onde vive o desempregado, influencia a procura de emprego e pode ser mais ou menos problemática e o contraste entre a situação no desemprego e a situação de empregado mais dicotómica.

\section{Discussão}

A tipologia construída para esta investigação mostra uma especificidade da sociedade portuguesa que é provável que seja partilhada, pelo menos em parte, pelos outros países do Sul da Europa: o desemprego está, no seu conjunto, pouco estigmatizado e os indivíduos a quem diz respeito conseguem de uma forma, mais o menos fácil, compensar esta privação: poucos são os indivíduos que vivem a privação de emprego sentindo humilhação aborrecimento. Mesmo esses, não estão excluídos socialmente : conservam contactos regulares e relações sociais quotidianas no quadro de vida ordinário que corresponde ao seu lugar social. Esta especificidade da sociedade portuguesa emerge com mais evidência quando confrontada com os estudos britânicos ou franceses onde a forma mais frequente de vivência do desemprego está aparentada com o sofrimento, com a humilhação, o aborrecimento e também a des-socialização.

A maioria dos desempregados em Portugal, pertencem a uma sociedade de "pobreza integrada" (Paugam, 1996: 394), para utilizar os conceitos do S. Paugam. Não conhecem de forma tão vincada a estigmatização e o sentimentos de vergonha, tanto mais que a sua inserção social e familiar e as possibilidades de trabalho informal são fortes.
O tipo-ideal, composto de três subtipos que correspondem cada um a um grupo de população distinta, remete a sociedade portuguesa no seu conjunto: menos salarial e menos governada pelo Estado-providência que outras sociedades da Europa ocidental.

Todavia, vemos aparecer as primeiras experiências do desemprego, características das sociedades salariais ou providenciais com um estatuto inferior, o aborrecimento, a dessocialização e a humilhação do desempregado, tal como as pesquisas sociológicas em França as têm analisado. Mas, mesmo neste caso, a experiência não é tão dolorosa que nas sociedades onde o Estado-providência é mais antigo e mais protector, porque as concepções tradicionais adoçam a prova. O desvio relativamente ao tipo-ideal pode ser interpretado como o efeito das mudanças em curso e a aparição dos primeiros efeitos do "desemprego total" (Schnapper, 1981) tal como foi analisado em França.

Para concluir, poder-se-á alargar o campo da reflexão encetada nesta investigação. A sociedade portuguesa mudou muito, complexificou-se extraordinariamente mas ficou com numerosos traços da cultura camponesa sem que esses constituam traços anacrónicos, frutos dum conservandorismo obstinado. Seria interessante compreender como podem evoluir as características de uma tal sociedade face ao aumento do nível de vida, à diversificação dos modos de vida e à abertura a modelos mais individualistas. Poder-se-á pensar, por exemplo, que a médio prazo, a participação maciça das mulheres no mercado de emprego vai modificar o seu estatuto na sociedade portuguesa. $\mathrm{O}$ facto de algumas mulheres fazerem a experiência de um "desemprego total nascente" pode ser o sinal de uma mudança da relação entre casa e trabalho. Poder-se-á também perguntar qual será o lugar da tal ética do trabalho numa sociedade que vai abrir-se, pouco a pouco, aos lazeres diversos, às férias, etc. Não seria também sem interesse observar até que ponto a ética de suporte mutuo poderá manter-se de forma tão estável, na sociedade portuguesa. 


\section{Bibliografia}

ASTIER, I., 1992, “Ce que chômeur veut dire: vrai ou faux chômeur? Apte ou inapte au travail?", Temps modernes, vol. 48, n. ${ }^{\circ} 554$

BURNAY, N., 2000, Chômeurs en fin de parcours professionnel. Avoir 50 ans, être au chômage, Lausana, Delachaux et Niestlé, col. "Actualités en sciences sociales".

VALA, J., 2000, "Mudanças nos valores associados ao trabalho e satisfação com o trabalho", in CABRAL, M. V. et al. (eds.), Atitudes sociais dos portugueses. Orientações perante o trabalho. Base de dados 1997, Lisboa, Instituto de Ciências Sociais da Universidade de Lisboa.

CAPUCHA, L. (ed.), 1998, Rendimento mínimo garantido: avaliação da fase experimental, Lisboa, Departamento de estudos, prospectiva e planeamento do Ministério do Trabalho e da Solidariedade.

DEMAZIERE, D., 1992, Le chômage en crise? La négociation des identités des chômeurs de longue durée, Lille, PUL.

DIAS, M., REIS, L. B., 1993, “Grupos e valores de referência socio-politicos", in FRANçA, L. (ed.), Portugal, valores europeus, identidade cultural, Lisboa, Instituto de estudos para o desenvolvimento.

FRANÇA, L., 1993, "Introdução", in FRANÇA, L. (ed.), Portugal, valores europeus, identidade cultural, Lisboa, Instituto de estudos para o desenvolvimento.

FREIRE, J., 1998, "Empresas e organizações: mudanças e modernização", in COSTA, A. F., VIEGAS, J. M. L (eds.), Portugal, que modernidade?, Oeiras, Celta.

GALLIE, D., VOGLER, C., 1994, "Unemployment and attitudes to work", in GALLIE, D., MARSH, C., VOGLER, C. (eds.), Social change and the experience of unemployment, Oxford, Oxford University Press.

GALLIE, D., PAUGAM, S. (eds.), 2000a, Welfare regimes and the experience of unemployment in Europe, Oxford, Oxford University Press.

GALLIE, D., PAUGAM, S., 2000b, "The experience of unemployment in Europe: the debate", in GALLIE, D., PAUGAM, S. (eds.), Welfare regimes and the experience of unemployment in Europe, Oxford, Oxford University Press.

GALLIE, D., PAUGAM, S., 2000c, "The social regulation of unemployment", in GALLIE, D., PAUGAM, S. (eds.), Welfare regimes and the experience of unemployment in Europe, Oxford, Oxford University Press.

GALLIE, D., MARSH, C., VOGLER, C. (eds.), 1994, Social change and the experience of unemployment, Oxford, Oxford University Press.

GALLIE, D., JACOBS, S., PAUGAM, S., 2000, "Poverty and financial hardship among the unemployed", in GALLIE, D., PAUGAM, S. (eds.), Welfare regimes and the experience of unemployment in Europe, Oxford, Oxford University Press.

GOUGH, I., 1996, "Social assistance in southern Europe", South european society and policies, vol. $1, \mathrm{n} .^{\circ} 1$.
LAZARSFELD, P., JAHODA, M., ZEISELP, H., 1931, Les chômeurs de Marienthal, Paris, Minuit, 1981 para a edição francesa.

LOISON, L., 2002, L'expérience vécue du chômage au Portugal, Tese para o doutoramento de Estado em Sociologia, Paris, Institut d'Etudes Politiques de Paris - Instituto Superior de Ciências do Trabalho e da Empresa de Lisboa.

NUNES, J. S. ,1998, "Perfis sociais juvenis", in CABRAL, M. V., PAIS, J. M. (eds.), Jovens portugueses de hoje. Resultados do inquérito de 1997, Oeiras, Celta, col. "Estudos sobre juventude".

PAIS, J. M., 1993, Culturas juvenis, Lisboa, Imprensa Nacional-Casa da Moeda.

PAUGAM, S., 1996, "Pauvreté et exclusion. La force des contrastes nationaux", in PAUGAM, S. (ed.), L'exclusion, l'état des savoirs, Paris, La découverte, col. "Textes à l'appui".

PAUGAM, S., RUSSELL, H., 2000, "The effects of unemployment precarity and unemployment on social isolation", in GALLIE, D., PAUGAM, S. (eds.), Welfare regimes and the experience of unemployment in Europe, Oxford, Oxford University Press.

PAUGAM, S., ZOYEM, J.P., CHARBONNEL, J. M., 1993, Précarité et risque d'exclusion en France, Paris, La documentation française, col. "Documents du CERC", n. ${ }^{\circ} 109$.

RAMOS, M. C., 1998, "Evolution du marché du travail au Portugal", in DUSAUTOY, M. (ed.) Intégration européenne et emploi. Le cas des pays semi-périphériques de l'Europe, Paris, Presses de la Sorbonne nouvelle.

RODRIGUES, M. J., LOPES, H., 1993, La place de l'entreprise dans le processus de formation professionnelle. Effets formateurs de l'organisation du travail, Centre européen pour le développement de la formation professionnelle - DINÂMIA.

RUSSELL, H., BARBIERI, P., 2000, "Gender and the experience of unemployment", in GALLIE, D., PAUGAM, S. (eds), Welfare regimes and the experience of unemployment in Europe, Oxford, Oxford University Press.

SCHNAPPER, D., 1994, L'épreuve du chômage, Paris, Gallimard, 1981, nova edição revistada e corrigida, col. "Folio".

VASCONCELOS, P., 1998a, "Práticas e discursos da conjugalidade e da sexualidade dos jovens portugueses", in CABRAL, M. V., PAIS, J. M. (eds.), Jovens portugueses de hoje. Resultados do inquérito de 1997, Oeiras, Celta, col. "Estudos sobre juventude".

VASCONCELOS, P., 1998b, "Vida familiar", in PAIS, J. M. (ed.), Gerações e valores na sociedade portuguesa contemporânea, Lisboa, Instituto de Ciências Sociais da Universidade de Lisboa.

WHELAN, C., McGINNITY, F., 2000, "Unemployment and satisfaction: an european analysis", in GALLIE, D., PAUGAM, S. (eds.), Welfare regimes and the experience of unemployment in Europe, Oxford, Oxford University Press, 2000. 